\title{
Does Preoperative Serum Neutrophil To Lymphocyte Ratio (NLR), Platelet To Lymphocyte Ratio (PLR) And Lymphocyte To Monocyte Ratio (LMR) Predict Prognosis Following Radical Surgery For Pancreatic Adenocarcinomas? - Results of A Retrospective Study.
}

Vikas Bachelal Gupta ( $\nabla$ veekyg4u@gmail.com )

MGM Medical College Kamothe https://orcid.org/0000-0002-0143-7445

Vikram Chaudhari

Tata Memorial Hospital

Shailesh V. Shrikhande

Tata Memorial Hospital

Manish S. Bhandare

Tata Memorial Hospital

\section{Research Article}

Keywords: Pancreatic cancer, Serum neutrophil to lymphocyte ratio (NLR), platelet to lymphocyte ratio (PLR), lymphocyte to monocyte ratio (LMR)

Posted Date: June 29th, 2021

DOI: https://doi.org/10.21203/rs.3.rs-513807/v1

License: (9) This work is licensed under a Creative Commons Attribution 4.0 International License. Read Full License

Version of Record: A version of this preprint was published at Journal of Gastrointestinal Cancer on August 18th, 2021. See the published version at https://doi.org/10.1007/s12029-021-00683-1. 


\section{Abstract}

\section{Background:}

Pretherapy serum neutrophil to lymphocyte ratio (NLR), platelet to lymphocyte ratio (PLR) and lymphocyte to monocyte ratio (LMR) have been shown to predict prognosis in patients with pancreatic ductal adenocarcinoma (PDAC). However, the published literature is conflicting, hence we aimed to evaluate their role in predicting survival outcomes in operated patients of PDAC.

\section{Methods:}

A retrospective analysis was done of all operated cases of PDAC who underwent curative resection between 2011 to 2018. The pretherapy NLR, PLR and LMR were calculated and analyzed with respect to pathological and survival outcomes

\section{Results:}

134 operated patients were included. The median overall survival for NLR of less than $2,2.7$ and 5 was 30.8 , 27.2 and 27.5 months and for NLR more than 2, 2.7 and 5 was 22.9, 21.6 and 21.5 months respectively and was statistically insignificant ( $p$-value- $0.32,0.91,0.34$ respectively). Similarly, the PLR was not significant for a cut off of 150 (p-value- 0.27 ) and LMR was not significant for a cut off of 2.8 (p-value- 0.13 ) and 4.8 ( $p$-value -0.11). On Univariate analysis age, CA 19-9, perineural invasion, margin positivity, lymph node positivity and TNM stage were found to have significant correlation with overall survival. However, on multivariate analysis, only TNM stage was found to be significant.

\section{Conclusion:}

The NLR, PLR and LMR do not correlate with overall survival in operated patients with PDAC in this study. A combination of inflammatory markers or their dynamic testing might probably achieve prognostic significance.

\section{Introduction}

With a continuous progress in development of newer and effective cancer related therapies, much improvement in survival has been achieved in many cancers. However, there has been hardly any headway when it comes to pancreatic ductal adenocarcinoma (PDAC) and it is still one of the most fatal cancers, with a 5-year survival rate of $5-10 \%[1]$. The main hindrance being difficulty in its early detection, as most patients are asymptomatic in early stages of cancer and the inherent aggressive tumor biology of PDAC. At the time of diagnosis $10-20 \%$ of tumors are operable, $30-40 \%$ are borderline resectable (BRPC), while remaining are either locally advanced or metastatic [2]. For advanced disease, palliative chemotherapy and/or radiotherapy remains the only treatment option.

Operable pancreatic cancers are generally divided into resectable and borderline resectable depending upon radiological features and relation to surrounding vessels, predicting the risk of margin positivity. This distinction is important, in order to offer neo adjuvant treatment in BRPCs, which has shown to increase the percentage of $\mathrm{R} 0$ resections and reduce lymph node positivity, thus reducing the risk of local recurrence [3]. A prognostic 
marker which can predict margin positivity in a seemingly upfront resectable tumour, will help in deciding the criteria of resectability and need of neo adjuvant chemotherapy in this patient population. However, this requires that patients are risk stratified before starting treatment. Radiological evaluation is not entirely accurate in distinguishing resectable from borderline tumours, as radiological findings do not always correlate with intraoperative findings and histopathological parameters. Contrast-enhanced computed tomography (CECT) has poor sensitivity (77\%) to predict vascular invasion and endoscopy ultrasound (EUS) has high false positives or negatives (33\%) to predict resection [4][6].

A number of systemic inflammation-based prognostic markers and scores have been studied to predict cancerspecific survival in several digestive cancers [5]. Out of these CA19-9 has been most commonly used in pancreatic cancers. However, use of CA 19 - 9 may not be accurate as few patients are non secretors (10-15\%), also some patients with obstructive jaundice will have spuriously elevated CA $19-9$ levels [6]. Previous studies concluded that level of serum neutrophil to lymphocyte ratio (NLR), platelet to lymphocyte ratio (PLR) and lymphocyte to monocyte ratio (LMR) might be associated with prognosis in several tumor types, including pancreatic cancers [7-12]. Although they are easy to measure, the number of neutrophils, monocytes and lymphocytes is influenced by immune status of body, which in turn is activated by host of other factors like active infection, chronic inflammatory diseases and lifestyle-related habits [13]. In the present study we aimed to assess the value of inflammation based markers namely NLR, PLR and LMR in predicting prognosis of operated PDAC patients

\section{Materials And Methodology}

Data was collected from a prospectively maintained surgical database of patients who underwent curative pancreatectomy for PDAC, between January 2010 and June 2019. Inclusion criteria were patients with histologically proven PDAC with imaging findings consistent with resectable or borderline resectable pancreatic cancers as per the AHPBA criteria [14], documented patient Eastern Cooperative Oncology Group (ECOG) performance status score of $<2$, who underwent curative intent surgery, either upfront or after neo-adjuvant therapy. Exclusion criteria included patient with metastatic disease on presentation, patients lost to follow up, patient who died in the immediate post-operative period and those in whom data was not available on pretreatment NLR, LMR and PLR. Each patient was reviewed by multidisciplinary joint team (MDT) comprising of HPB surgeon, medical oncologist, radiation oncologist, radiologist and pathologist, for planning treatment. Patients with borderline resectable cancers were offered neoadjuvant chemotherapy /chemoradiation or upfront surgery as per discretion of MDT.

The NLR was calculated from the differential leucocyte count by dividing the absolute neutrophil count by the absolute lymphocyte count. Similarly the PLR (platelet count by the absolute lymphocyte count) and the LMR (absolute lymphocyte count by the absolute monocyte count) were also calculated. The ratios were then divided into two groups using cut off values; for NLR we used cut off values of 2.7 (mean NLR), 2 and 5. For PLR, 150 and for LMR, 2.8 and 4.8 were used as cut offs. Patient who were upfront resectable had their blood samples collected within 1 month before surgery and those planned for NACT had their values obtained from blood sample taken just before starting chemotherapy. All patients who were planned for neoadjuvant chemotherapy or chemoradiation or surgery, showed no signs of systemic inflammation or infection as noted at the time of laboratory testing. For patients having obstructive jaundice, all blood test results were re-assessed 
after procedures such as endoscopic retrograde cholangiopancreatography (ERCP) and percutaneous transhepatic biliary drainage (PTBD), once jaundice had resolved; before planning surgery.

Statistical test:

Continuous variables were compared using Student's t-test and categorical variables were compared using the chi-squared test. Survival curves were calculated using the Kaplan-Meier method and compared using Log rank test to evaluate difference in survival. Survival curves were compared using the cut off values already mentioned. $P$ values less than 0.05 were considered statistically significant. The factors associated with OS in univariate analysis were used for the performance of the multivariate Cox-regression analysis. The statistical analyses were performed with the Statistical Package of the Social Sciences (SPSS), version 17.0.

\section{Results}

Overall, 1144 patients underwent surgery between 2010 to 2018 for pancreatic and periampullary tumors. 708 patients had tumors of periampullary origin and 260 were of non adenocarcinoma histology. Follow up data was not available for 20 patients and pre therapy blood parameter records were not available of 5 patients. There were 17 post-operative deaths. After excluding these cases, 134 patients were available for final analysis who underwent curative resections for pancreatic adenocarcinoma. All patients underwent either pancreatico duodenectomy (PD) or radical antegrade modular pancreatico-splenectomy (RAMPS).

There were slightly more females than males and most of the cancers were pancreatic head adenocarcinomas (85.8\%).76 patients (56.7\%) were upfront resectable and 58 (43.3\%) were borderline resectable according to radiological evaluation. 40 (29.9\%) patients received neo adjuvant therapy (37- chemotherapy, 3 chemoradiation). Adjuvant chemotherapy was given to 110 patients (82.1\%). 32 (24.3\%) out of 132 patients had margin positivity. Most patients were T3 (43.3\%) and there were almost equal number of node positive $(54.5 \%)$ and node negative $(45.5 \%)$ patients. (Table 1,2$)$

Table 1

Laboratory tests of resected patients.

\begin{tabular}{|ll|}
\hline Variable & Median (min, max) \\
\hline ANC $\left(10^{9} / \mathrm{I}\right)$ & $5(2,10)$ \\
\hline AMC $\left(10^{9} / \mathrm{I}\right)$ & $0.4(0.1,1.2)$ \\
\hline ALC $\left(10^{9} / \mathrm{I}\right)$ & $1.9(0.1,5.3)$ \\
\hline Platelets $\left(10^{9} / \mathrm{L}\right)$ & $288(77,674)$ \\
\hline Serum Albumin $(\mathrm{g} / \mathrm{dL})$ & $3.9(2.7-5.2)$ \\
\hline Neutrophil/lymphocyte ratio & $2.7(0.38-76)$ \\
\hline Platelet/lymphocyte ratio & $196.8(20.8-2440)$ \\
\hline Lymphocyte / monocyte ratio & $4.8(0.27-17)$ \\
\hline
\end{tabular}


Table 2

Clinical, operative and pathological features of resected patient.

\begin{tabular}{|c|c|}
\hline Characteristics & Number (Percentage) \\
\hline Age, years (range) & $56(22-80)$ \\
\hline$<65$ & $108(80.6)$ \\
\hline$>65$ & $26(19.4)$ \\
\hline \multicolumn{2}{|l|}{ Gender } \\
\hline Male & $81(60.4)$ \\
\hline Female & $53(39.6)$ \\
\hline \multicolumn{2}{|l|}{ Location of tumour } \\
\hline Head of pancreas & $115(85.8)$ \\
\hline Body / tail of pancreas & $17(12.7)$ \\
\hline Neck of pancreas & $2(1.5)$ \\
\hline \multicolumn{2}{|l|}{ CA19-9 ( U/mL) } \\
\hline$<200$ & $81(60.4)$ \\
\hline$>200$ & $53(39.6)$ \\
\hline \multicolumn{2}{|l|}{ Type of Resection } \\
\hline Pancreaticoduodenectomy & $114(85)$ \\
\hline Distal Pancreatectomy & $12(8.95)$ \\
\hline Total/ subtotal Pancreatectomy & $8(5.9)$ \\
\hline Neoadjuvant therapy & $40(29.9)$ \\
\hline Chemotherapy & $37(27.6)$ \\
\hline Chemoradiation & $3(2.2)$ \\
\hline \multicolumn{2}{|l|}{ Adjuvant therapy } \\
\hline Chemotherapy & $110(82.1)$ \\
\hline Observation & $24(17.9)$ \\
\hline \multicolumn{2}{|l|}{ Pathologic features } \\
\hline \multicolumn{2}{|l|}{ Histological differentiation } \\
\hline Moderate & $104(77.6)$ \\
\hline Poor & $30(22.4)$ \\
\hline Perineural invasion present & $73(54.4)$ \\
\hline
\end{tabular}




\begin{tabular}{|ll|}
\hline Characteristics & Number (Percentage) \\
\hline Lymphovascular invasion present & $54(40.3)$ \\
\hline Margin positivity $(\mathrm{n}=132)$ & \\
\hline R0 & $100(75.7)$ \\
\hline R1 & $32(24.3)$ \\
\hline AJCC/TNM 8th Ed. & \\
\hline pT Stage & \\
\hline T1 & $17(12.7)$ \\
\hline T2 & $43(32.1)$ \\
\hline T3 & $58(43.3)$ \\
\hline T4 & $16(11.9)$ \\
\hline pN stage & \\
\hline N0 & $61(45.5)$ \\
\hline N1 & $53(39.6)$ \\
\hline N2 & $20(14.9)$ \\
\hline Stage & \\
\hline IA & $16(11.9)$ \\
\hline IB & $19(14.2)$ \\
\hline IIA & $26(19.4)$ \\
\hline IIB & $41(30.6)$ \\
\hline III & $32(23.9)$ \\
\hline
\end{tabular}

The mean absolute Lymphocyte, Monocyte, Neutophil and platelet counts were $1.9 \times 10^{9} / \mathrm{I}, 0.4 \times 10^{9} / \mathrm{I}, 5 \times 10^{9} / \mathrm{I}$ and $288 \times 10^{9} /$ respectively, and the mean NLR, LMR, PLR values were 2.7, 195 and 4.8 respectively. KaplanMeier method was used to calculate survival curves and survival was compared using Log rank test. Age more than 65 years ( $p-0.008), C A 19-9$ more than $200 \mathrm{U} / \mathrm{mL}$ ( $p-0.002)$, presence of perineural invasion ( $\mathrm{p}-0.036)$, margin positivity(p-0.044), lymph node positivity $(0.039)$ and higher TNM stage $(0.002)$ were found to have worse OS. On univariate analysis stage of disease (p-0.001,HR - 3.54, 95\% $\mathrm{Cl} 1.69-7.44)$, age with cut off 65 years (p-0.010,HR - 2.03, 95\% Cl 1.18-3.49), CA 19 - 9 for a cut off $200 \mathrm{U} / \mathrm{mL}$ (p-0.016,HR - 1.83, 95\% Cl 1.312.96 ) peri neural invasion ( $\mathrm{p}-0.040, \mathrm{HR}-0.59,95 \% \mathrm{Cl} 0.36-0.97)$, and lymph node positivity ( $\mathrm{p}-0.04, \mathrm{HR}-0.60$, $95 \% \mathrm{Cl} 0.37-0.98$ ) were found to have significant correlation with overall survival. However on multi variate analysis only TNM stage ( $\mathrm{p}-0.02, \mathrm{HR}-2.97,95 \% \mathrm{Cl} 1.13-.7 .77)$ was found to be significant. None of the inflammation based markers namely NLR, PLR and LMR were found to correlate with overall survival (Table 3). 
Table 3

Univariate and multivariate Cox proportional hazards analysis of patient and tumour related factors for overall survival.

\begin{tabular}{|c|c|c|c|c|c|c|c|c|c|}
\hline \multirow{3}{*}{ Variable } & & \multicolumn{4}{|c|}{ Univariate } & \multicolumn{4}{|c|}{ Multivariate } \\
\hline & & \multirow{2}{*}{$\begin{array}{l}\text { Hazard } \\
\text { ratio }\end{array}$} & \multicolumn{2}{|c|}{$95.0 \% \mathrm{Cl}$} & \multirow{2}{*}{$\begin{array}{l}\mathrm{P} \\
\text { value }\end{array}$} & \multirow{2}{*}{$\begin{array}{l}\text { Hazard } \\
\text { ratio }\end{array}$} & \multicolumn{2}{|c|}{$95.0 \% \mathrm{Cl}$} & \multirow{2}{*}{$\begin{array}{l}\mathrm{P} \\
\text { value }\end{array}$} \\
\hline & & & Lower & Upper & & & Lower & Upper & \\
\hline \multicolumn{10}{|c|}{ Patient-related factors } \\
\hline \multirow[t]{2}{*}{ Age } & $<=65$ & & & & & & & & \\
\hline & $>65$ & 2.036 & 1.187 & 3.493 & 0.010 & 1.64 & 0.93 & 2.89 & 0.088 \\
\hline \multirow[t]{2}{*}{ Sex } & Male & & & & & & & & \\
\hline & Female & 1.058 & .652 & 1.718 & 0.820 & & & & \\
\hline \multirow[t]{2}{*}{ CA19-9 } & $<200$ & & & & & & & & \\
\hline & $>200$ & 1.831 & 1.131 & 2.965 & 0.014 & 0.63 & 0.379 & 1.078 & 0.093 \\
\hline \multirow[t]{2}{*}{ NLR- 2.7} & $<2.7$ & & & & & & & & \\
\hline & $>2.7$ & .975 & .609 & 1.563 & .918 & & & & \\
\hline \multirow[t]{2}{*}{ NLR - 2} & $<2$ & & & & & & & & \\
\hline & $>2$ & 1.307 & .769 & 2.222 & .323 & & & & \\
\hline \multirow[t]{2}{*}{ NLR- 5} & $<5$ & & & & & & & & \\
\hline & $>5$ & 1.400 & .694 & 2.824 & .348 & & & & \\
\hline \multirow[t]{2}{*}{ PLR - 150} & $<150$ & & & & & & & & \\
\hline & $>150$ & .767 & .477 & 1.234 & .275 & & & & \\
\hline \multirow[t]{2}{*}{ LMR- 4.8} & $<4.8$ & & & & & & & & \\
\hline & $>4.8$ & .673 & .409 & 1.108 & .119 & & & & \\
\hline \multirow[t]{2}{*}{ LMR - 2.8} & $<2.8$ & & & & & & & & \\
\hline & $>2.8$ & .666 & .388 & 1.142 & .139 & & & & \\
\hline \multirow{2}{*}{$\begin{array}{l}\text { Neoadjuvant } \\
\text { Therapy }\end{array}$} & Yes & & & & & & & & \\
\hline & No & 1.442 & .843 & 2.467 & .181 & & & & \\
\hline \multicolumn{10}{|c|}{ Tumour -related factors } \\
\hline \multirow{2}{*}{$\begin{array}{l}\text { Tumor } \\
\text { Differentiation }\end{array}$} & MDAC & & & & & & & & \\
\hline & PDAC & .610 & .850 & 2.956 & .140 & & & & \\
\hline
\end{tabular}




\begin{tabular}{|c|c|c|c|c|c|c|c|c|c|}
\hline & & \multicolumn{4}{|c|}{ Univariate } & \multicolumn{4}{|c|}{ Multivariate } \\
\hline \multirow[t]{2}{*}{ LVE } & Absent & & & & & & & & \\
\hline & Present & .813 & .460 & 1.217 & .242 & & & & \\
\hline \multirow[t]{2}{*}{ PNI } & Absent & & & & & & & & \\
\hline & Present & .595 & 0.364 & 0.971 & .038 & 0.72 & 0.42 & 1.23 & 0.229 \\
\hline \multirow[t]{2}{*}{ Margins } & Free & & & & & & & & \\
\hline & Involved & 1.721 & 1.007 & 2.942 & .047 & 1.11 & 0.59 & 2.09 & 0.751 \\
\hline \multirow[t]{2}{*}{ LN status } & Negative & & & & & & & & \\
\hline & Positive & 0.606 & .375 & .980 & .041 & 1.17 & 0.60 & 2.26 & 0.652 \\
\hline \multirow[t]{2}{*}{ pT stage } & T3 ,T4 & & & & . & & & & \\
\hline & $\begin{array}{l}\text { versus } \\
\mathrm{T} 1, \mathrm{~T} 2\end{array}$ & 1.577 & .618 & 4.020 & .340 & & & & \\
\hline \multirow[t]{2}{*}{ TNM Stage } & III & & & & & & & & \\
\hline & $\begin{array}{l}\text { versus I } \\
\text { and II }\end{array}$ & 3.54 & 1.690 & 7.443 & .001 & 2.97 & 1.13 & 7.77 & 0.027 \\
\hline
\end{tabular}

\section{Discussion}

There is a significant difference in the biological behavior and prognosis of pancreatic cancers, with patients within same stage also having varied final outcomes. To identify some markers which can predict survival, may help us further prognosticate these patients and ultimately assist in decision making. An ideal prognostic marker should give us information on the long-term prognosis of patients, help us in making a comprehensive treatment plan including sequencing of surgery, chemotherapy and or radiotherapy and also in predicting margin and lymph nodal status before surgery [2]. The prognostic marker should best correlate with the pathological and clinical stage of disease. The most accurate information on outcomes following surgery are obtained from post operative histological parameters like tumour size, nodal status, margin status, pathological stage of the disease [15]. However, to make an effective treatment plan, patients need to be risk stratified before surgery [7]. In the present study age, CA19-9, peri neural invasion, margin positivity, lymph node positivity, and TNM stage of disease was found to have significant association with overall survival. None of the inflammation based marker ratios, namely NLR, PLR or LMR were found to have correlation with overall survival.

Inflammation is one of the hallmarks of carcinogenesis and plays an important role in tumour progression [16]. Neutrophils are among the first cells to migrate to site of inflammation. They in turn release chemokines and protease which further recruit other effector cells [17]. On the other hand, lymphocyte count correlates with the systemic immune response that the host can mount, and tumor-infiltrating lymphocytes (specifically $T$ cells) 
are responsible for mounting the antitumor response within the microenvironment [18]. As far as platelets and cancer cells are concerned they are known to interact with each other during tumorigensis. Cancer cells bring about platelet adhesion, platelet activation and degranulation with resultant pro-survival and pro-angiogenic signals which may promote cancer spread $[19,20]$. Literature on use of these blood cell based markers is inconsistent with few studies showing either no or some implication [15, 21-26] while others concluding their usefulness in prognostication of disease $[6-8,27,28]$. Although most studies including metanalysis have shown favorable outcomes with the use of pro inflammatory markers for prognosis, there is considerable variation in the type of marker used, timing of blood sample collection and the cut off value of marker.

In a recently published retrospective study assessing the role of NLR and PLR for resectable pancreatic cancers, no significant association was found between this markers and survival for a range of cut off values [21]. Similarly prospective study by Jamieson et all studying the prognostic Value of Tumor and Patient related Factors in Patients Undergoing potentially Curative Surgery for PDACs did not find either NLR or PLR to be associated significantly with survival for cut off values of 5 and 150 respectively [15]. Other studies assessing multiple parameters have shown survival to be unrelated to atleast one or more of these markers (NLR ,PLR or LMR). In one of the studies with 74 resected pancreatic cancers, NLR was found to be significantly associated with disease free survival at a cut off of 5 , but no difference was seen with $C$ reactive protein (CRP) or PLR [22]. One of larger retrospective studies found significant association between NLR (cut off of 5 ) and overall survival for both resected and inoperable pancreatic cancers. However, no significance was seen for PLR (cut off of 150) [27]. Likewise, retrospective cohort study by Sierzega et a (442 patients) found NLR and LMR to be associated with survival, but no relation was seen with PLR [29]. (Table 4) 
Table 4

Published literature on prognostic applications of NLR, LMR, and PLR in resected pancreatic cancer.

\begin{tabular}{|c|c|c|c|c|c|c|c|}
\hline Study & Year & Number & Variable & Cut off & Cohorts & $\begin{array}{l}\text { Median overall } \\
\text { Survival(months) }\end{array}$ & $\begin{array}{l}\text { (p value). } \\
\text { Significance }\end{array}$ \\
\hline $\begin{array}{l}\text { Clark et al } \\
\text { [25] }\end{array}$ & 2007 & 44 & NLR & $<5 / \geq 5$ & $40 / 4$ & $10.5 / 8.9$ & $(0.16), \mathrm{NS}$ \\
\hline \multirow{3}{*}{$\begin{array}{l}\text { Bhatti et } \\
\text { al[34] }\end{array}$} & 2010 & 84 & NLR & $\leq 4 />4$ & $71 / 13$ & $14 / 7.1$ & $(0.004), S$ \\
\hline & & & & $\begin{array}{l}\leq 3 / 3- \\
4 />4\end{array}$ & $55 / 17 / 12$ & $13.7 / 17 / 5.9$ & $(0.016), S$ \\
\hline & & & PLR & $\begin{array}{l}< \\
100 / 100- \\
200 />200\end{array}$ & $35 / 39 / 10$ & $14.4 / 10.3 / 8$ & $(0.642), \mathrm{NS}$ \\
\hline \multirow{2}{*}{$\begin{array}{l}\text { Garcea et } \\
\text { al[22] }\end{array}$} & 2011 & 74 & NLR & $<5 />5$ & - & 52/12 (DFS) & $(0.0057), S$ \\
\hline & & & PLR & - & - & - & NS \\
\hline \multirow{2}{*}{$\begin{array}{l}\text { Jamieson } \\
\text { et al [15] }\end{array}$} & 2011 & 135 & NLR & $<5 / \geq 5$ & $105 / 30$ & $20.9 / 25.7$ & (0.510), NS \\
\hline & & & PLR & $\begin{array}{l}<150 / \\
\geq 150\end{array}$ & $42 / 93$ & $26.7 / 20.7$ & $(0.21), \mathrm{NS}$ \\
\hline $\begin{array}{l}\text { La Torre } \\
\text { et al [24] }\end{array}$ & 2012 & 101 & NLR & $\leq 5 />5$ & $81 / 20$ & $21 / 17$ & $(0.13), \mathrm{NS}$ \\
\hline \multirow{2}{*}{$\begin{array}{l}\text { Sanjay et } \\
\text { al [26] }\end{array}$} & 2012 & 51 & NLR & $\leq 5 />5$ & $38 / 13$ & $16.2 / 9.1$ & $(0.272), \mathrm{NS}$ \\
\hline & & & PLR & $\begin{array}{l}< \\
150 / 150- \\
300 />300\end{array}$ & $16 / 25 / 10$ & $15.9 / 15 / 4.1$ & $(0.532), \mathrm{NS}$ \\
\hline \multirow[t]{2}{*}{$\begin{array}{l}\text { Smith et } \\
\text { al[35] }\end{array}$} & & 110 & NLR & Continuous & Continuous & - & $\begin{array}{l}\text { Not } \\
\text { significant } \\
(0.14)\end{array}$ \\
\hline & & & PLR & $\begin{array}{l}< \\
150 / 150- \\
300 />300\end{array}$ & 48/43/19 & 19.7/13.7/5.8 & $(0.0001)$ \\
\hline \multirow{2}{*}{$\begin{array}{l}\text { Stotz et } \\
\text { al [27] }\end{array}$} & 2013 & 110 & NLR & $<5 />5$ & 73/37 & - & $(0.006), S$ \\
\hline & & & PLR & $\begin{array}{l}<150 / \\
\geq 150\end{array}$ & $28 / 82$ & - & $(0.458), \mathrm{NS}$ \\
\hline $\begin{array}{l}\text { Hamed et } \\
\text { al [23] }\end{array}$ & 2013 & 85 & NLR & $<5 / \geq 5$ & $67 / 18$ & 20.6/11.3 & $(0.15), \mathrm{NS}$ \\
\hline $\begin{array}{l}\text { Sierzega } \\
\text { et al [29] }\end{array}$ & 2017 & 442 & NLR & $<5 />5$ & $323 / 119$ & $25 / 12.6$ & $(0.012), S$ \\
\hline
\end{tabular}

NLR -neutrophil to lymphocyte ratio, PLR- platelet to lymphocyte ratio, LMR- lymphocyte to monocyte ratio, NS- Not significant, S- Significant $(P<0.05)$ 


\begin{tabular}{|c|c|c|c|c|c|c|c|}
\hline Study & Year & Number & Variable & Cut off & Cohorts & $\begin{array}{l}\text { Median overall } \\
\text { Survival(months) }\end{array}$ & $\begin{array}{l}\text { (p value). } \\
\text { Significance }\end{array}$ \\
\hline & & & LMR & $<3 / \geq 3$ & $247 / 195$ & $13.1 / 29.2$ & $(0.026), \mathrm{S}$ \\
\hline \multirow{3}{*}{$\begin{array}{l}\text { Onoe et } \\
\text { al [9] }\end{array}$} & 2019 & 165 & NLR & $<3.2 / \geq 3.2$ & $117 / 48$ & - & $(0.046), S$ \\
\hline & & & PLR & $\begin{array}{l}<250 / \\
\geq 250\end{array}$ & $132 / 33$ & - & $(0.014), S$ \\
\hline & & & LMR & $<2.8 / \geq 2.8$ & $25 / 140$ & $8.7 / 18.5$ & $(0.015), S$ \\
\hline \multirow{6}{*}{$\begin{array}{l}\text { Current } \\
\text { study }\end{array}$} & 2020 & 134 & NLR & $<2 / \geq 2$ & $35 / 99$ & $30.8 / 22.9$ & $(0.91), \mathrm{NS}$ \\
\hline & & & & $<2.7 / \geq 2.7$ & $66 / 68$ & $27.2 / 21.6$ & (0.32), NS \\
\hline & & & & $<5 / \geq 5$ & $122 / 12$ & $27.5 / 21.5$ & $(0.34), \mathrm{NS}$ \\
\hline & & & PLR & $\begin{array}{l}<150 / \\
\geq 150\end{array}$ & $59 / 75$ & $24 / 27.2$ & $(0.27), \mathrm{NS}$ \\
\hline & & & LMR & $<4.8 / \geq 4.8$ & $79 / 55$ & $21.5 / 30.8$ & $(0.11), \mathrm{NS}$ \\
\hline & & & & $<2.8 / \geq 2.8$ & $29 / 105$ & $20.3 / 27.5$ & (0.13), NS \\
\hline
\end{tabular}

There are at least 3 meta analysis conducted to look into the prognostic significance of this markers $[10,11$, 12]. One of the initial meta analysis by yang et al (11 studies and 1804 patients) had a diverse patient population with few studies consisting of locally advanced cancers treated with chemotherapy, others having resected pancreatic cancer patients and stills others having a combination of both resected and locally advanced patients [11]. Another meta anlaysis of 1519 patients with 8 studies [12] which looked into only resected pancreatic cancers found significant association between NLR (cut off values ranging from 2 to 5 ) and survival. Nevertheless, most of this were studies conducted in Asian population and this may be a confounding factor in validating the outcomes of this analysis into other population groups. Recently published larger meta analysis of 8252 patients [10] consisting of heterogeneous study groups also found a significant association between NLR and survival. Even the subgroup analysis of surgery alone trials, as also analysis based on ethnic origin of the patients showed positive results. Again the surgery alone trials were predominantly conducted in Asian countries and the subgroup of Caucasian trials predominantly involved non surgical treatment, thus making comparison between study groups debatable. Surgery alters the natural course of disease process, thus it might not be correct to club resected and inoperable patients together as a common cohort while analyzing the results of the study. Moreover the cut-off value of NLR and sample size of included cohorts varied from 2 to 5 and 28 to 474 , respectively.

With considerable improvement in survival over past decades and corresponding decrease in morbidity [30] ,identification of prognostic markes should help us in further improving patient outcomes . However our study did not find any significant association between this markers and overall survival and although the survival was better with low NLR and high LMR for all cut offs, it did not reach statistical significance. One of the reasons for this may be that, although individually this test may not be predictive of survival, a combination of two or more 
of these variables may be a better marker to assess prognosis. The systemic immune-inflammation index (SII), calculated with lymphocyte, neutrophil, and platelet counts has been shown to be an independent negative predictor of disease-free survival in resectable PDAC [31] as well as OS when evaluated as a continuous variable rather than pre operative value in patients given neo adjuvant chemotherapy [32]. It has also been shown to be better than neutrophil-to-lymphocyte ratio (NLR) or the platelet-to-lymphocyte ratio (PLR) for prediction of OS in patients with resectable PDAC [33]. Also as inflammatory markers are dynamic, they may change during the treatment course. Thus instead of assessing this variables at a point in time, looking at change of values over the course of treatment might be a better way of utilizing their potential. This may be of significance as neo adjuvant approach is being increasingly used to treat borderline resectable pancreatic cancers. Glazer et all in their study of BRPCs did not find NLR value alone ( pre and post chemo ) as predictive of survival ,but increase in values over course of chemotherapy to be associated with poor survival post resection [28].

The main limitation of our study is its single center, retrospective design. Larger, multicenter studies will give better answer to the applicability of these markers. To summaries although literature is replete with studies that have show correlation of survival with pro inflammatory markers, there applicability is still contentious. Many of the studies had heterogeneous population groups with regards to management (surgical or nonsurgical), cut off value used, timing of sample collection, presence of associated inflammatory condition, and tumor stage. Thus, there is still an ambiguity involved in using these markers for the purpose of prognostication. Further larger trials using combination of markers measured pre operatively for upfront resectable patients or assessing response of this markers following neo adjuvant treatment for BRPC are needed. Till robust data on their use is available it may be counterproductive if these markers are used for definitive decision making

\section{Conclusion}

The NLR, PLR and LMR were not found to correlate with overall survival in operated patients with pancreatic ductal adenocarcinomas in our study. A combination of inflammatory markers or their dynamic testing might probably achieve prognostic significance.

\section{Declarations}

\section{Contribution of authors:}

VG, MB VC, SS were involved in the conception and design of the work;

VG, MB involved in acquisition, analysis, interpretation of data and manuscript preparation.

MB, VC, SS involved in manuscript editing, manuscript review

All authors read and approved the manuscript.

\section{COMPLIANCE WITH ETHICAL STANDARDS}

The data of the present study were collected in the course of common clinical practice, and accordingly, the signed informed consent was obtained from each patient for any surgical and clinical procedure. The study

Page 12/16 
protocol was in accordance with the ethical standards of the institutional research committee and the 1964 Helsinki Declaration and its later amendments. Because this was a retrospective study, formal consent for this study is not required and no approval of the institutional research committee was needed.

FINANCIAL SUPPORT: None

CONFLICT OF INTEREST: None

\section{References}

1) Ferrone $C R$, Pieretti-Vanmarcke R, Bloom JP et al. Pancreatic ductal adenocarcinoma: long-term survival does not equal cure. Surgery 2012; 152: S43-9.

2) Kim WJ, Lim TW, Park PJ, Choi SB, Kim WB. Prognostic impact of the combination of the neutrophil-tolymphocyte ratio and serum carbohydrate antigen 19-9 in patients with pancreas head cancer. ANZ J Surg. 2019 Jul;89(7-8):E302-E307

3) Ueda M, Endo I, Nakashima M et al. Prognostic factors after resection of pancreatic cancer. World J. Surg. 2009; 33: 104-10.

4) Tamburrino D, Riviere D, Yaghoobi M, Davidson BR, Gurusamy KS. Diagnostic accuracy of different imaging modalities following computed tomography (CT) scanning for assessing the resectability with curative intent in pancreatic and periampullary cancer. Cochrane Database Syst Rev. 2016 ;9:CD011515

5) Roxburgh CS, McMillan DC. Role of systemic inflammatory response in predicting survival in patients with primary operable cancer. Future Oncology. 2010; 6(1): 149-163.

6) Bergquist JR, Puig CA, Shubert CR, et al. Carbohydrate Antigen 19-9 Elevation in Anatomically Resectable, Early Stage Pancreatic Cancer Is Independently Associated with Decreased Overall Survival and an Indication for Neoadjuvant Therapy: A National Cancer Database Study. J Am Coll Surg 2016;223:52-65.

7) Recio-Boiles A, Nallagangula A, Veeravelli S, et al. Neutrophil-to-lymphocyte and platelet-to-lymphocyte ratios inversely correlate to clinical and pathologic stage in patients with resectable pancreatic ductal adenocarcinoma. Ann Pancreat Cancer. 2019;2:8

8) Giakoustidis A, Neofytou K, Costa Neves M, et al. Identifying the role of neutrophil-to-lymphocyte ratio and platelets-to-lymphocyte ratio as prognostic markers in patients undergoing resection of pancreatic ductal adenocarcinoma. Ann Hepatobiliary Pancreat Surg. 2018;22(3):197-207.

9) Onoe S, Maeda A, Takayama Y, et al. The Prognostic Impact of the Lymphocyte-to-Monocyte Ratio in Resected Pancreatic Head Adenocarcinoma. Med Princ Pract. 2019;28(6):517-525

10) Zhou $\mathrm{Y}$, Cheng S, Fathy AH, et al. Prognostic value of platelet-to-lymphocyte ratio in pancreatic cancer: a comprehensive meta-analysis of 17 cohort studies. Onco Targets Ther 2018;11:1899-908.

11) Yang JJ, Hu ZG, Shi WX, et al. Prognostic significance of neutrophil to lymphocyte ratio in pancreatic cancer: a meta-analysis. World J Gastroenterol 2015;21:2807-15

Page 13/16 
12) Mowbray NG, Griffith D, Hammoda M, Shingler G, Kambal A, Al-Sarireh B. A meta-analysis of the utility of the neutrophil-to-lymphocyte ratio in predicting survival after pancreatic cancer resection. HPB (Oxford). 2018;20(5):379-384.

13) Buyukkaya E, Karakas MF, Karakas E, et al. Correlation of neutrophil to lymphocyte ratio with the presence and severity of metabolic syndrome. Clin App/ Thromb Hemost. 2014;20(2):159-163

14) Callery MP, Chang KJ, Fishman EK, Talamonti MS, William Traverso L, Linehan DC. Pretreatment assessment of resectable and borderline resectable pancreatic cancer: expert consensus statement. Ann Surg Oncol. 2009;16:1727-33.

15) Jamieson NB, Denley SM, Logue J, MacKenzie DJ, Foulis AK, Dickson EJ, et al. A prospective comparison of the prognostic value of tumor- and patient-related factors in patients undergoing potentially curative surgery for pancreatic ductal adenocarcinoma. Ann Surg Oncol 2011;18:2318-2328

16) Hanahan D, Weinberg RA. Hallmarks of cancer: the next generation. Cell. 2011;144(5):646-74.

17) SA Weitzman, AB Weitberg, EP Clark, TP Stossel.Phagocytes as carcinogens: malignant transformation produced by human neutrophils Science.1985; 227:1231-1233

18) Man YG, Stojadinovic A, Mason J, et al. Tumor-infiltrating immune cells promoting tumor invasion and metastasis: existing theories. J Cancer 2013;4:84-95.

19) Jenne CN, Urrutia R, Kubes P. Platelets: bridging hemostasis, inflammation, and immunity. Int J Lab Hematol 2013;35:254- 261.

20) Egan K, Crowley D, Smyth P, O'Toole S, Spillane C, Martin C, et al. Platelet adhesion and degranulation induce pro-survival and pro-angiogenic signalling in ovarian cancer cells. PLoS One 2011;6:e26125.

21) Chawla A, Huang TL, Ibrahim AM, Hardacre JM, Siegel C, Ammori JB. Pretherapy neutrophil to lymphocyte ratio and platelet to lymphocyte ratio do not predict survival in resectable pancreatic cancer. HPB (Oxford). 2018;20(5):398-404

22) Garcea G, Ladwa N, Neal CP, Metcalfe MS, Dennison AR, Berry DP. Preoperative neutrophil-to-lymphocyte ratio (NLR) is associated with reduced disease-free survival following curative resection of pancreatic adenocarcinoma. World J Surg 2011;35:868-872.

23) Hamed MO, Roberts KJ, Smith AM, Morris Stiff G. Elevated pre-operative neutrophil to lymphocyte ratio predicts disease free survival following pancreatic resection for periampullary carcinomas. Pancreatology. 2013;13(5):534-538

24) La Torre M, Nigri G, Cavallini M, Mercantini P, Ziparo V, Ramacciato G. The glasgow prognostic score as a predictor of survival in patients with potentially resectable pancreatic adenocarcinoma. Ann Surg Oncol 2012;19:2917-2923.

25) Clark EJ, Connor S, Taylor MA, Madhavan KK, Garden OJ, Parks RW. Preoperative lymphocyte count as a prognostic factor in resected pancreatic ductal adenocarcinoma. HPB (Oxford) 2007;9:456-460 
26) Sanjay P, de Figueiredo RS, Leaver H, Ogston S, Kulli C, Polignano FM, et al. Preoperative serum C-reactive protein levels and post-operative lymph node ratio are important predictors of survival after pancreaticoduodenectomy for pancreatic ductal adenocarcinoma. JOP 2012;13:199-204

27) Stotz M, Gerger A, Eisner F, et al. Increased neutrophil-lymphocyte ratio is a poor prognostic factor in patients with primary operable and inoperable pancreatic cancer .Br J Cancer. 2013;109(2):416-421

28) Glazer ES, Rashid OM, Pimiento JM, Hodul PJ, Malafa MP. Increased neutrophil-to-lymphocyte ratio after neoadjuvant therapy is associated with worse survival after resection of borderline resectable pancreatic ductal adenocarcinoma. Surgery. 2016;160(5):1288-1293.

29) Sierzega M, Lenart M, Rutkowska M, et al. Preoperative Neutrophil-Lymphocyte and Lymphocyte-Monocyte Ratios Reflect Immune Cell Population Rearrangement in Resectable Pancreatic Cancer. Ann Surg Oncol. 2017;24(3):808-815.

30) Shrikhande SV, Shinde RS, Chaudhari VA, et al. Twelve Hundred Consecutive Pancreato-Duodenectomies from Single Centre: Impact of Centre of Excellence on Pancreatic Cancer Surgery Across India [published online ahead of print, 2019 Oct 22]. World J Surg. 2019;10.1007/s00268-019-05235-0.

31) Aziz MH, Sideras K, Aziz NA, et al. The systemic-immuneinflammation index independently predicts survival and recurrence in resectable pancreatic cancer and its prognostic value depends on bilirubin levels: a retrospective multicenter cohort study. Ann Surg. 2018;270:139-46.

32) Murthy P, Zenati MS, Al Abbas Al, et al. Prognostic Value of the Systemic Immune-Inflammation Index (SII) After Neoadjuvant Therapy for Patients with Resected Pancreatic Cancer. Ann Surg Oncol. 2020;27(3):898-906

33) Jomrich G, Gruber ES, Winkler D, et al. Systemic Immune-Inflammation Index (SII) Predicts Poor Survival in Pancreatic Cancer Patients Undergoing Resection. J Gastrointest Surg. 2020;24(3):610-618.

34) Bhatti, O. Peacock, G. Lloyd, M. Larvin, R.I. Hall. Preoperative hematologic markers as independent predictors of prognosis in resected pancreatic ductal adenocarcinoma: neutrophil-lymphocyte versus plateletlymphocyte ratio. Am. J. Surg. 2010;200:197-203..

35) Smith RA, Bosonnet L, Raraty M, Sutton R, Neoptolemos JP, Campbell F, et al. Preoperative plateletlymphocyte ratio is an independent significant prognostic marker in resected pancreatic ductal adenocarcinoma. Am J Surg 2009;197:466- 472.

\section{Figures}



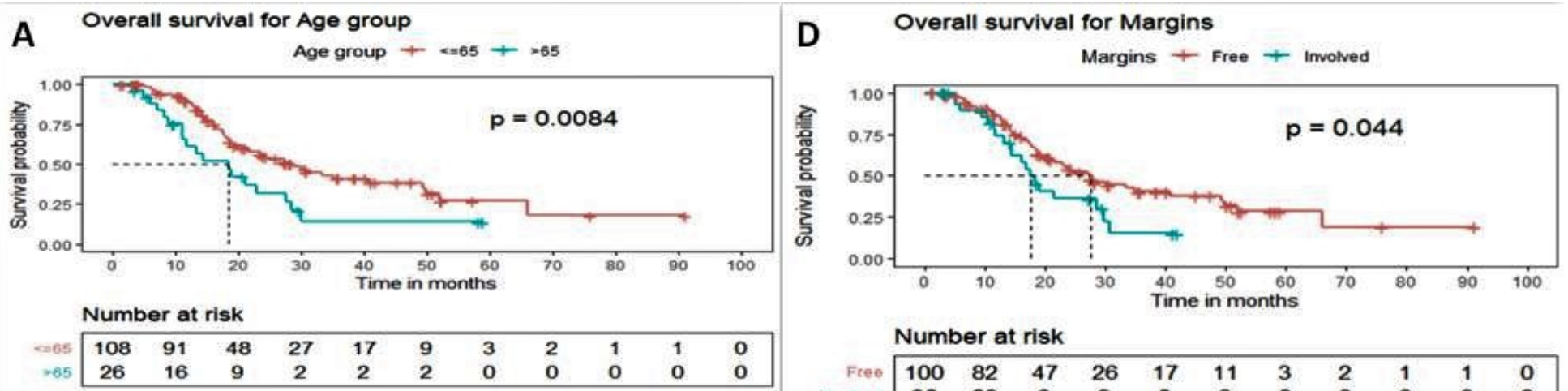

Overall survival for CA19.9

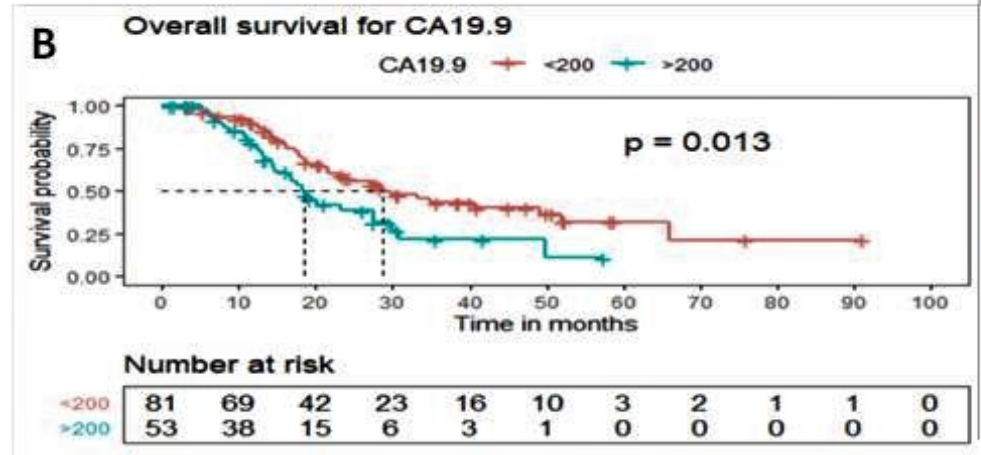

Number at risk
\begin{tabular}{|ccccccccccc|}
100 & 82 & 47 & 26 & 17 & 11 & 3 & 2 & 1 & 1 & 0 \\
32 & 23 & 9 & 3 & 2 & 0 & 0 & 0 & 0 & 0 & 0 \\
\hline Invotved
\end{tabular}
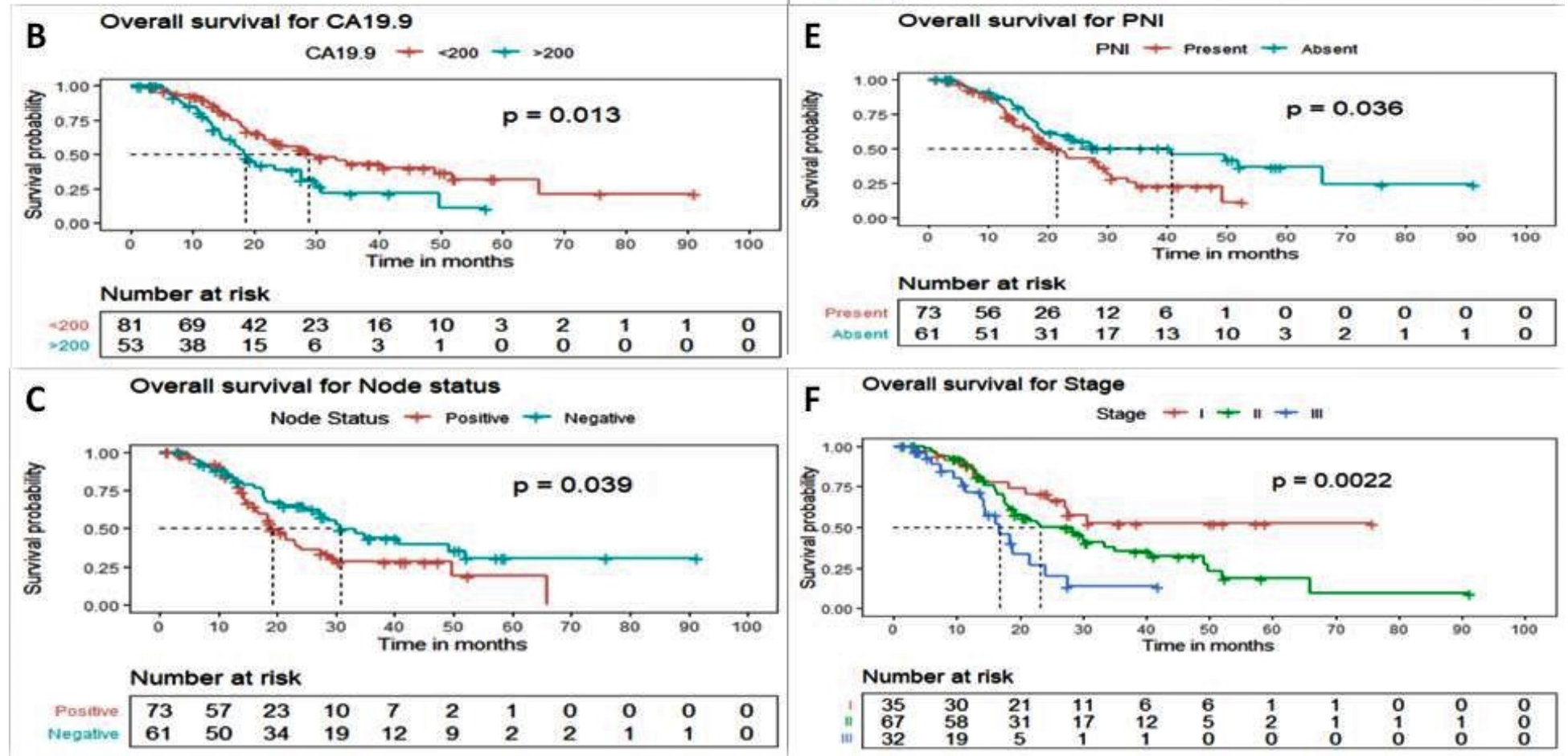

Figure 1

Kaplan-Meier survival analysis demonstrated worse OS for patients who had age more than 65 years (A), had CA 19-9 more than 200 (B), were node positive (C), had margin positivity (D) , had peri neural invasion (E) and those with higher stage $(F),(p<0.05)$. 